\title{
CT-GUIDED STEREOTAXY: FIRST 10-YEAR EXPERIENCE
}

\author{
Miroslav Heřman ${ }^{\text {a*}}$, Petr Dvoř́ak ${ }^{\mathrm{b}}$, Michael Houdek ${ }^{\mathrm{b}}$
}

a Clinic of Radiology, Teaching Hospital Olomouc, Czech Republic

b Clinic of Neurosurgery, Teaching Hospital Olomouc, Czech Republic

e-mail: herman@fnol.cz

Received: October 14, 2004; Accepted: November 3, 2003

Key words: Stereotaxy / CT / Brain biopsy / Intracerebral hematoma / Fibrinolysis / Parkinson's disease / Complications

The authors present an overview on CT-guided stereotaxy performed in the last 10 years in the University Hospital Olomouc. During this period a total of 811 stereotactic brain operations were performed. Of these, 710 were done in the field of afunctional and 101 in the field of functional stereotaxy. The majority of procedures were biopsies of intracranial lesions $(n=464)$, evacuations of intracerebral hematomas with or without drainage and fibrinolysis $(n=147)$ and thalamotomies in patients with Parkinson's disease $(n=88)$. With the exception of the two years at the beginning, the number of yearly performed stereotaxies varied between 66-106 (mean, 86.9). Serious complications appeared after three procedures $(0.37 \%)$.

\section{INTRODUCTION}

Stereotactic neurosurgery is indissolubly linked to imaging methods. The introduction of computed tomography (CT) into clinical practice had resulted in the unexpected expansion of stereotaxy. CT has made possible the precise localization of intracranial targets together with targeted structures, and this has contributed to the further expansion of stereotaxy, especially in afunctional area.

The first CT was put into operation in our hospital in April 1989. Immediately adjacent to the CT equipment, an operating theatre for stereotactic procedures was build. This close connection offers excellent spatial conditions for the performance of this kind of surgery.

The goal of this paper is to give an overview of CTguided stereotactic operations and the evolution of performed procedures during the first ten years.

\section{PATIENTS AND METHODS}

Between September 1989 and December 1999, 811 stereotactic brain operations were carried out on 785 patients at the University Hospital in Olomouc. (Our hospital has approximately 1500 beds and neurosurgery serves an area up to 1 million people.)

The Riechert-Mundinger stereotactic apparatus (Fischer, Germany) and the CT device Somatom DRH (Siemens, Germany) were used in all operations. In general, we used the following approach: the frame of the stereotactic apparatus was attached to the skull of the patient under local anesthesia in the stereotactic operating theater. The patient was thereafter transported to the CT and placed on a CT table to which the frame was firmly fixed. CT-compatible localizing markers were then attached to the frame and CT examination was performed. After imaging, the patient was transported back to the stereotactic operating theater, where the operating equipment of the stereotactic apparatus was attached to the frame and the actual surgery was performed. The technique we used for determination of targets on CT has already been described ${ }^{1,2}$.

The majority of operations were performed on conscious patients using local anesthesia only. General anesthesia was necessary only in nine uncooperative patients as well as in 19 patients with intracerebral hematomas who had already been intubated.

\section{RESULTS}

The first CT-guided stereotactic operation was performed at the Teaching Hospital in Olomouc in September 26, 1989. This was an evacuation of spontaneous intracerebral hematoma. Stereotactic diagnostic biopsies of brain tumors were the subsequent type of operations. During the first 4 months, 10 stereotactic operations were carried out. The first CT-guided functional stereotactic operation took place on October 23, 1990. During the following years, the number of stereotactic operations increased and their spectrum was broadened (tables 1-3). Apart from the first two years when the number of operations was lower, we yearly carried out between 66 and 106 stereotactic operations (an average of 86.9 per year). 
Table 1. Numbers of CT-guided afunctional and functional stereotactic operations performed in individual years in the Teaching Hospital Olomouc.

\begin{tabular}{|c|r|r|r|r|r|r|r|r|r|r|r|}
\hline Year & $1989 *$ & 1990 & 1991 & 1992 & 1993 & 1994 & 1995 & 1996 & 1997 & 1998 & 1999 \\
\hline Afunctional procedures & 10 & 17 & 55 & 56 & 93 & 77 & 82 & 77 & 74 & 80 & 88 \\
\hline Functional procedures & 0 & 2 & 11 & 16 & 13 & 25 & 15 & 7 & 9 & 0 & 4 \\
\hline Total & 10 & 19 & 66 & 72 & 106 & 102 & 97 & 84 & 83 & 80 & 92 \\
\hline
\end{tabular}

* from September 26, 1989

Table 2. Types and numbers of CT-guided afunctional stereotactic operations performed in our hospital.

\begin{tabular}{|l|r|}
\hline Type of procedure & Number \\
\hline Biopsy & 464 \\
\hline Evacuation of an intracerebral hematoma & 33 \\
Evacuation + drainage and fibrinolysis & 147 \\
of an intracerebral hematoma & \\
\hline Evacuation of an abscess & 7 \\
Evacuation + drainage of an abscess & 10 \\
\hline Evacuation of a coloid cyst & 6 \\
Cyst endoscopy & 3 \\
Implantation of a Salmon-Rickham ventil & 10 \\
\hline Hypophysectomy & 3 \\
\hline Stereotactically-guided craniotomy & 27 \\
\hline Total & 710 \\
\hline
\end{tabular}

Table 3. Numbers of CT-guided functional stereotactic operations performed in our hospital.

\begin{tabular}{|l|c|}
\hline Illnes & Number \\
\hline Parkinson's disease & 88 \\
Torticollis & 4 \\
Athetosis & 2 \\
\hline Idiocy combined with agression & 5 \\
Sexual deviancy & 2 \\
\hline Total & 101 \\
\hline
\end{tabular}

As can be seen from tables 2 and 3, diagnostic biopsies were the most frequent stereotactic operations performed $(n=464)$ (Fig. 1). A diagnostic tissue sample was obtained in 427 biopsies ( $92.0 \%$ ). In the remaining cases, the most frequent tissue sampling failures were related to the presence of necrosis or inflammatory changes. These problems were more frequent during the first 3 years when we did not use contrast-enhanced scans for targeting the lesion and we only compared findings with previously obtained enhanced CT scans. Later we started to use enhanced scans for targeting regularly, and this led to improvement in obtaining diagnostic tissue samples. If part of the lesion was liquid, this part was aspirated during the procedure. In most patients with expansively behaving lesions, the aspiration of the cystic part had a temporary therapeutic effect.

Aspiration of intracerebral or intracerebellar hematomas was performed in the first few years in the subacute phase. Later we started to carry out such operations in acute phase, when however, it became necessary to connect aspiration to drainage and fibrinolysis with repeated applications of urokinase. A detailed analysis of this group of patients has already been published ${ }^{3}$.

Abscess evacuation was performed in 17 patients. In 10 of these cases the evacuation was followed by drainage (Fig. 2). Treatment was successful in all cases.

Stereotactic evacuation of a colloid cyst, connected in two cases with cystostomy, was successful in five patients. In one case the cyst refilled after aspiration. Endoscopy was performed in three patients with cysts - one colloid and two arachnoid. A Salmon-Rickham ventil was implanted in seven patients with arachnoid cysts and also in three patients with inoperable cystic tumors for the relief of expansive effects. In all cases, the appropriate result was achieved.

Stereotactic hypophysectomy had a satisfactory therapeutic effect in all three patients with generalized prostatic carcinoma - considerable degree of pain relief was achieved.

In the past six years, we have started to take advantage of the possibilities of stereotactically-guided craniotomy. Stereotactic guidance has made it possible to significantly reduce the extent of craniotomy performed on smaller superficial lesions and, in cases of deeper lesions, it has provided precise guidance to the right spot.

The greatest number of operations in the area of functional stereotaxy has been performed on patients with extrapyramidal syndromes, especially Parkinson's disease $(\mathrm{n}=88)$. Seventeen were subsequently operated bilaterally (to eliminate possible fatal complications this operation was not performed on both sides in one session). During the operation on the opposite side the calculated position of the target could be checked and compared according to the localization of the contralateral lesion (Fig. 3). Only in three cases out of 17 the lesion from previous operation was not detected by CT performed during second operation. Enduring success of stereotactic operations on patients with Parkinson's disease was achieved in 76 cases (84.4 percent). A decrease in symptoms, especially tremor, was achieved in the remaining cases. In all patients 
with torticollis, athetosis and choreoathetosis respectively an improvement was achieved but not all symptoms were completely abolished.

Psychosurgical operations were performed on seven patients. Five patients suffered from a combination of idiocy and aggression - in all of them an amelioration of aggressive behavior was achieved. Further two patients were sexual deviants, both of whom underwent psychological-psychiatric testing, which showed a significant decrease in their aggressive sexual behavior after stereotactic operaton.
Serious complications occurred after three operations $(0.37 \%)$ two of them following functional stereotactic operations - thalamotomies for Parkinson's disease. In the first case it was an epidural hematoma located in the place of the calvarian hole. The hematoma was successfully surgically evacuated. In the second case, hematoma appeared at the place of operation target as well as on the access trajectory. This patient was treated conservatively with a resulting mild neurological deficit. The third complication was bleeding into the tumor (multiforme glioblastoma) after the performance of a diagnostic biopsy. As a consequence of bleeding the patient died within six days.

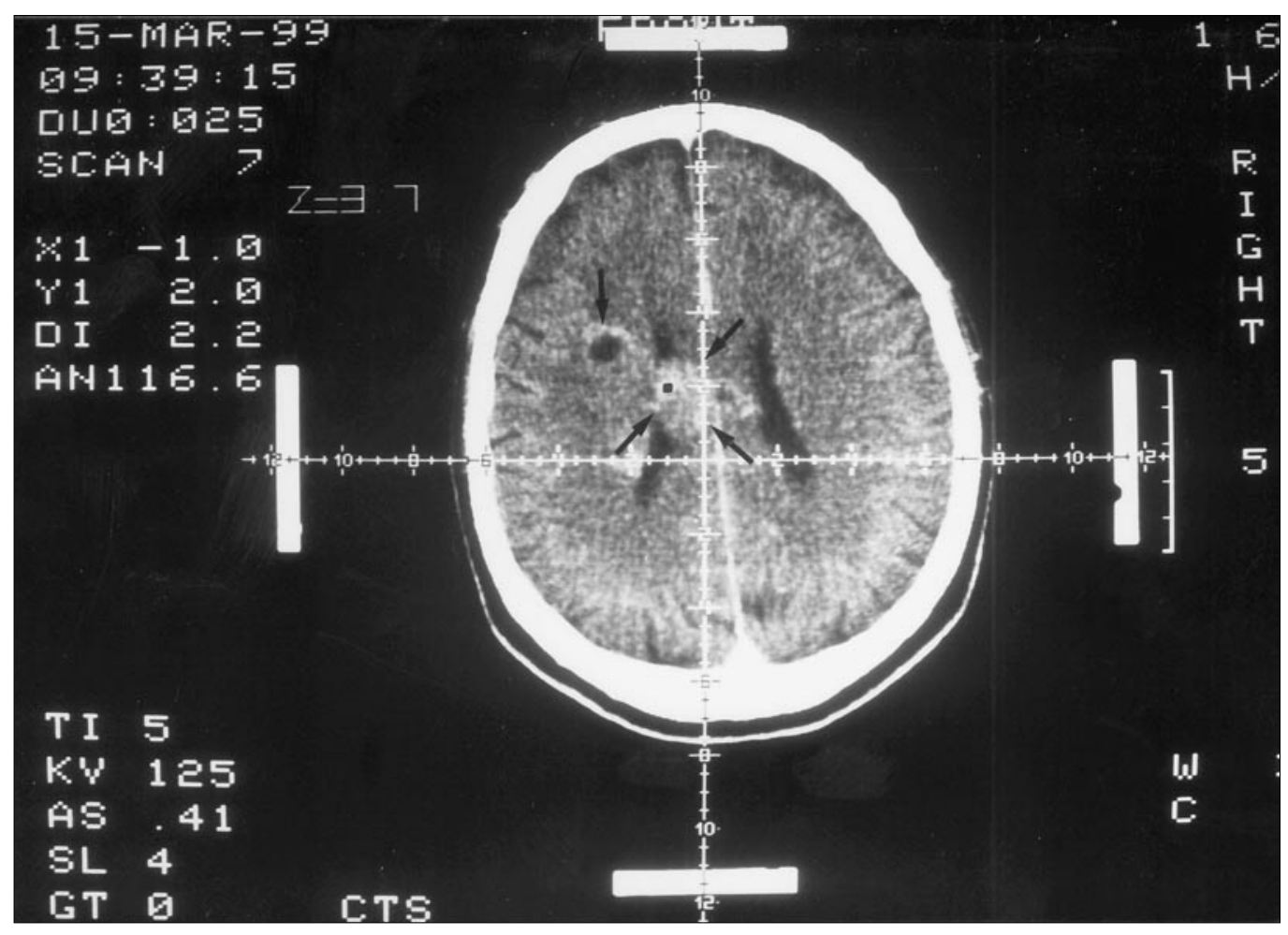

Fig. 1. Stereotactic tumor biopsy. A CT scan after intravenous application of contrast material demonstrates enhancing lesion in the left centrum semi-ovale and corpus callosum (arrows). Black dot shows position of the stereotactic target. After positioning the calibrated grid to the image and placing the cursor to the selected place, CT software automatically calculates coordinates $x$ and $y$ of the stereotactic target (shown on the left side - X1, Y1 - in centimeters). The value of $z$ coordinate was calculated from the CT table position and checked on markers visible on CT scan in bone window. Histology from the obtained specimen in this case proved glioblastoma multiforme. 


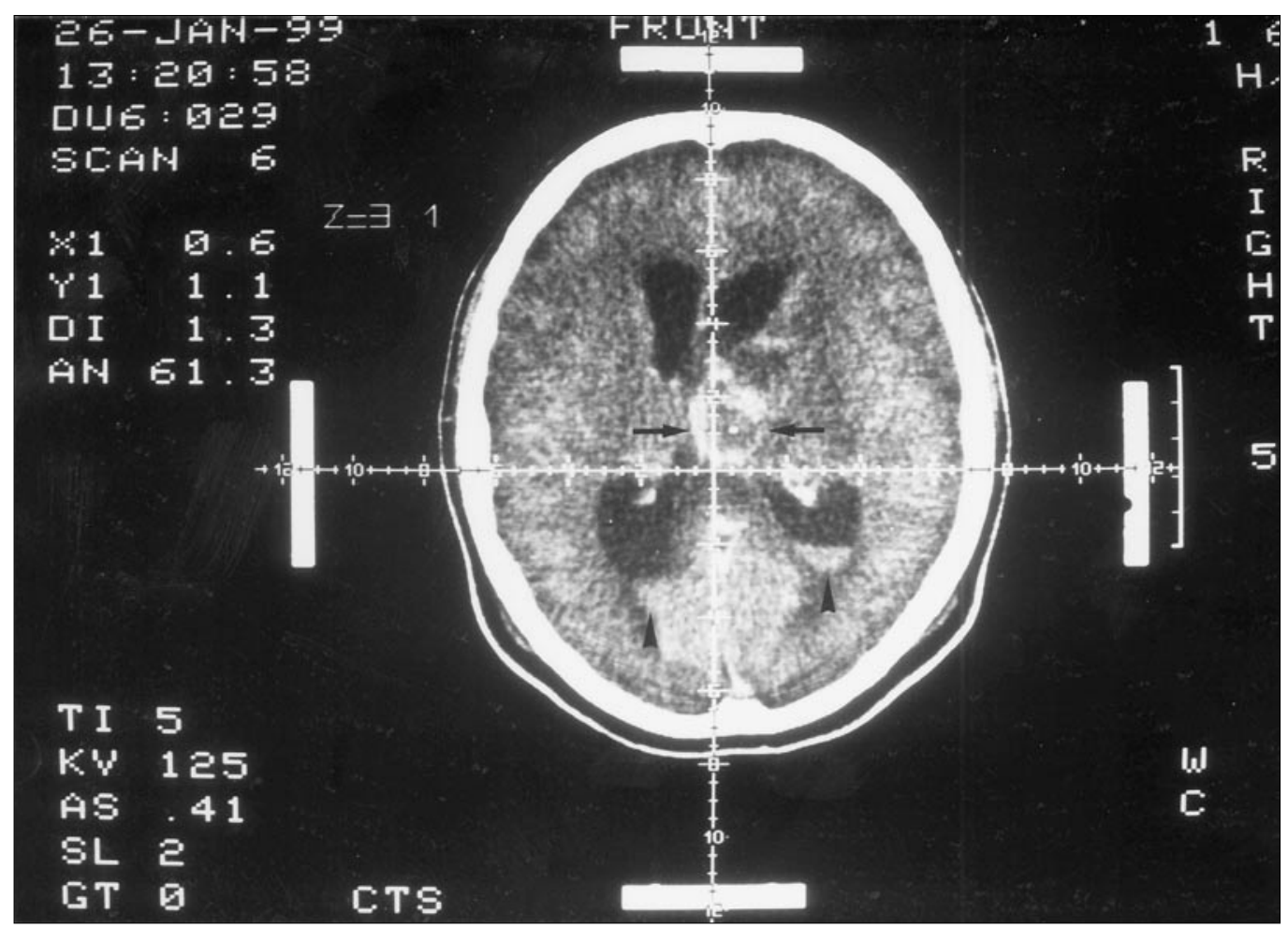

Fig. 2. Stereotactically guided evacuation and drainage of a brain abscess. CT scan after intravenous application of contrast material demonstrates ring-shaped enhancing lesion (arrows) with hypodense center in the right thalamus. Small amount of blood is seen in the dependent parts of lateral ventricles (arrowheads). White dot in the center of the lesion shows position of the stereotactic target. The content of the cavity was aspirated and a thin drain was inserted. For five days the cavity was repeatedly rinsed with antibiotics, then the drain was removed. Systemic antibiotic treatment continued for next two weeks. Following CT controls showed complete healing of the lesion, patient had no neurological deficit.

a)

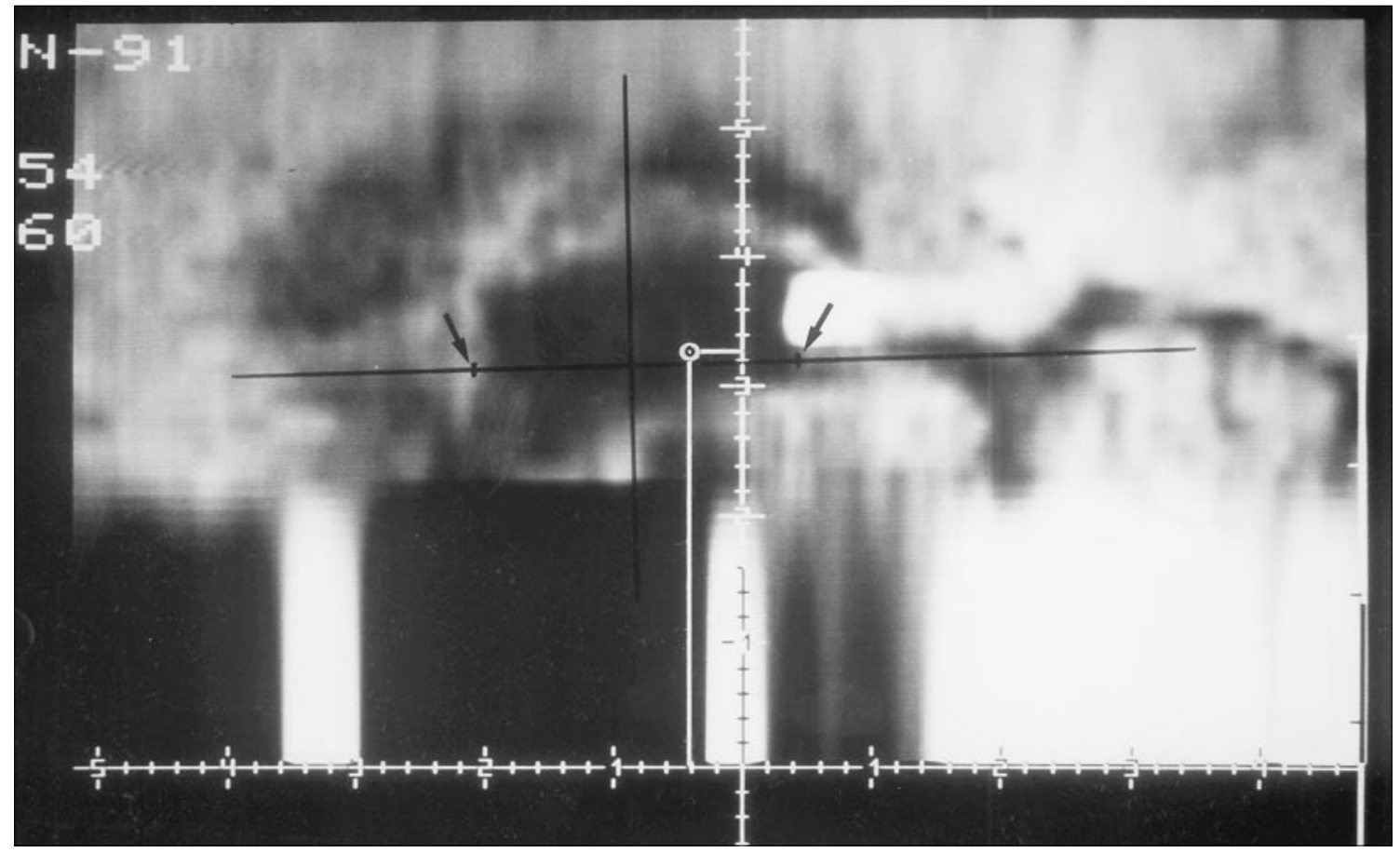

Fig. 3a. Functional stereotaxy in a patient with Parkinson's disease. a) To calculate target position in the ventro-oral thalamus, first sagittal reconstruction of the CT scans was performed and position of the anterior and posterior commissures were identified (black arrows). Coordinate system based on intercommissural line was drawn into the printed image (black lines) and value of $z$ and $y$ coordinates of the target $(O)$ were defined (white lines). 
b)

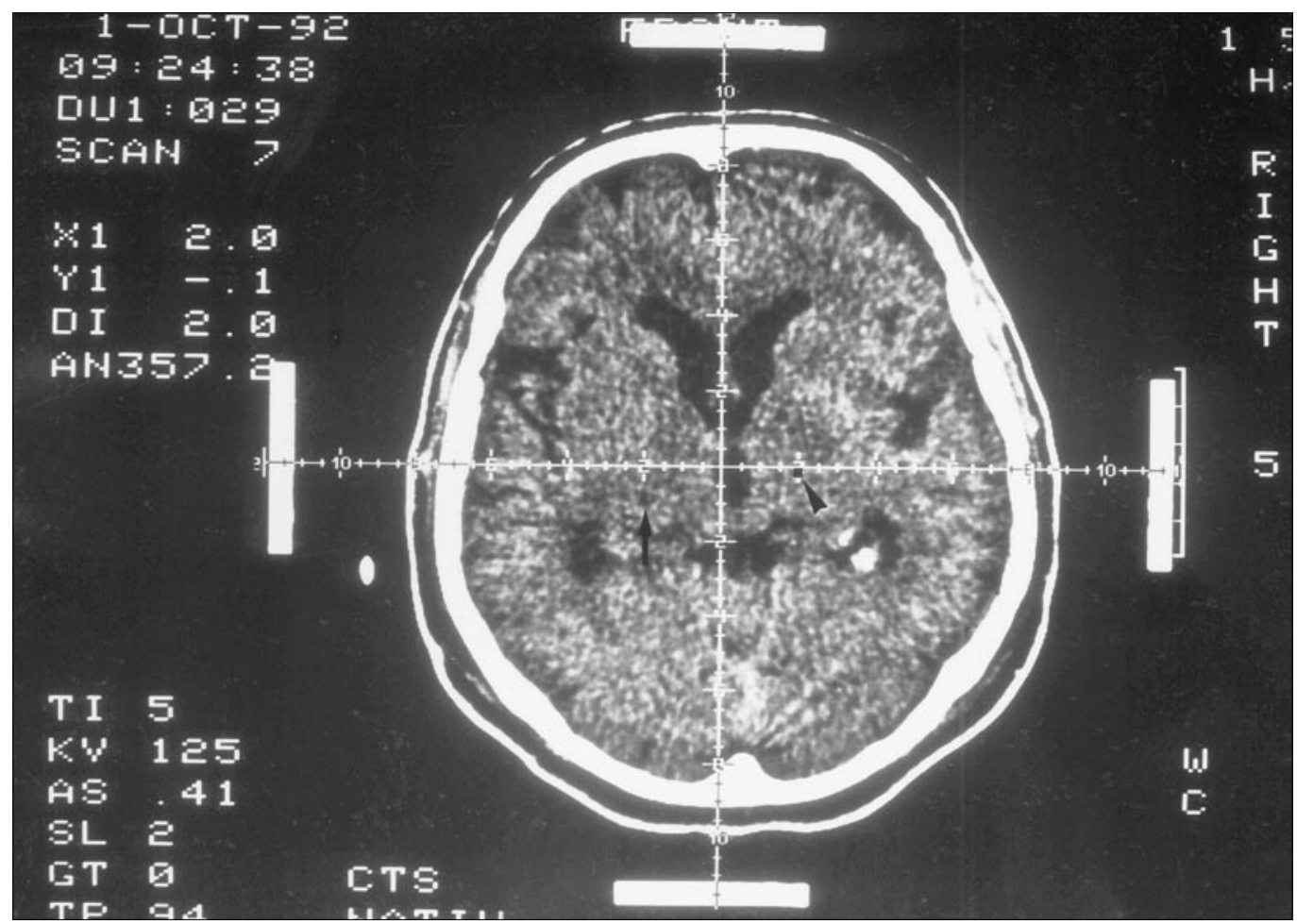

Fig. 3b. Functional stereotaxy in a patient with Parkinson's disease. b) Then CT scan obtained in the relevant position was used to determine $x$ coordinate of the target (arrowhead). Since this patient had undergone the same operation on the oposite side six months before, the lesion formed at the previous operation was noticeable as a minor hypodensity in the contralateral thalamus (arrow).

\section{DISCUSSION}

Biopsy is referred in large series as the most frequently performed stereotactic operation ${ }^{4,5,6}$. Our case was not different - biopsies made up more than half of all our operations. The importance of the biopsy lies in its ability to state the histological diagnosis of pathological process. On this base, the most suitable therapeutic approach can then be determined ${ }^{2,4,6,7}$. To obtain a diagnostic tissue sample, an optimal target point must be found. Regions showing high contrast enhancement were found to be the most appropriate not only according to our experience ${ }^{4}$.

Stereotactic evacuation of spontaneous intracerebral hematomas represents a modern method for treatment of this serious condition. Hematomas in a subacute or chronic stage (older than 4 days) can usually be aspirated to a greater or lesser extent. However, evacuation in this time is not very significant - it may only contribute to a faster reconvalescence of the patient. Evacuation of hematoma in the acute stage can prevent the initial phase of irreversible changes to the brain tissue in the neighborhood of the hematoma and in this way reduce the eventual neurological deficit. This is only possible to achieve, if the operation is carried out within 24 hours after onset of symptoms. However, in this acute stage, when the hematoma is made up primarily of blood clot, simple evacuation is not possible - it is necessary to perform drainage, fibrinolysis and repeated aspirations of liquiefied portions of hematoma 9 .
Further operations in the area of afunctional stereotaxy (apart from biopsies and the evacuation of intracerebral hematomas) make up only a small part of the total set of our operations. This situation is different in other centers where radiosurgical operations or computer assisted volumetric stereotactic resection are performed. There, these procedures are among the most frequently performed types of stereotactic operations ${ }^{9,10,11 .}$

Functional stereotaxy dominated stereotactic operations in the era before the beginning of the use of dopamine preparations for the treatment of extrapyramidal syndromes. After their introduction into clinical practice it seemed that stereotaxy would become obsolete. This did not happen, partly thanks to the CT which opened possibilities for performing new types of procedures especially in afunctional area. Later it was shown that the pharmacological treatment of extrapyramidal syndromes is not successful in all cases. For this reason stereotactic procedures in functional area are still performed, although to a lesser extent than previously ${ }^{12,13,14}$. Our experience confirms this. Patients suffering from extrapyramidal syndromes are satisfied with this type of treatment as is shown by their returning for a second operation on the opposite side, when their problems are bilateral.

The data shown above indicate the value and relative safety of stereotactic techniques. Our experience demonstrates that the spectrum of stereotactic operations performed with basic equipment is broad and can help patients suffering from different kind of diseases. Future 
development trends in stereotactic neurosurgery are above all, in the areas of radiosurgery, volumetric resection of expansive lesions and frameless stereotaxy with intraoperative imaging $6,10,11,15-19$. These methods, however, are connected with the use of sophisticated and expensive equipment.

\section{REFERENCES}

1. Heřman M, Houdek M, Nádvorník P. (1991) Využití výpočetni tomografie ve funkční stereotaktické neurochirurgii. Čas Lék čes 130, 640-4.

2. Heřman M, Dvořák $\mathrm{P}$, Houdek M. (2002) Zobrazovací metody ve stereotaktické neurochirurgii mozku. Postgrad Med 4, 856-68.

3. Hrabálek L, Houdek M, Dvořák P, Heřman M. (1996) CT-řízená stereotaktická léčba spontánních intracerebrálních hematomů s použitím urokinázy. Čs Neurol Neurochir 59/92, 319-25.

4. Apuzzo MLJ, Chandrasoma PT, Cohen D, Zee C-S, Zelman V. (1987) Computed imaging stereotaxy: experience and perspective related to 500 procedures applied to brain masses. Neurosurgery 20, 930-7.

5. Gomez H, Barnett GH, Estes ML, Palmer J, Magdinec M. (1993) Stereotactic and computer-assisted neurosurgery at the Cleveland Clinic: review of 501 consecutive cases. Cleve Clin J Med 60 399-410.

6. Lunsford LD, Coffey RJ, Cojocaru T, Leksell D. (1990) Imageguided stereotactic surgery: a 10-year evolutionary experience. Stereotact Funct Neurosurg 54, 375-87.
7. Field M, Witham TF, Flickinger JC, Kondziolka D, Lunsford LD. (2001) Comprehensive assessment of hemorrhage risks and outcome after stereotactic brain biopsy. J Neurosurg 94, 545-51.

8. Krupa P, Stilhart B, Coscia S, Tournade A. (1994) Využití CT pro stereotaktické probatorní biopsie sporných patologických afekcí mozku. Čes Radiol 48, 64-7.

9. Mohadjer M, Braus DF, Myers A, Scheremet R, Krauss JK. (1992) CT-stereotactic fibrinolysis of spontaneous intracerebral hematomas. Neurosurg Rev 15, 105-10.

10. Kelly PJ. (1991) Technique of computer assisted volumetric stereotactic resection. Acta Neurochir 52 Suppl, 30-2.

11. Kelly PJ. Tumor stereotaxis. Philadelphia, WB Saunders, 1991.

12. Eskandar EN, Shinobu LA, Penney JB Jr, Cosgrove GR, Counihan TJ. (2000) Stereotactic pallidotomy performed without using microelectrode guidance in patients with Parkinson's disease: surgical technique and 2-year results. J Neurosurg 92, 375-83.

13. Pahwa R, Lyons K, Koller WC. (2000) Surgical treatment of essential tremor. Neurology 54, S39-S44.

14. Intemann PM, Masterman D, Subramanian I, DeSalles A, Behnke E, Frysinger R, Bronstein JM. (2001) Staged bilateral pallidotomy for treatment of Parkinson disease. J Neurosurg 94 437-44.

15. Kelly PJ. (2000) Stereotactic surgery: what is past is prologue. Neurosurgery 46, 16-27.

16. Hall WA, Liu H, Martin AJ, Truwit CL. (2000) Intraoperative magnetic resonance imaging. Top Magn Reson Imaging 11, 203-12.

17. McInerney J, Roberts DW. (2000) Frameless stereotaxy of the brain. Mt Sinai J Med 67, 300-310.

18. Samset E, Hirschberg H. (1999) Neuronavigation in intraoperative MRI. Comput Aided Surg 4, 200-7.

19. Wadley J, Dorward N, Kitchen N, Thomas D. (1999) Pre-operative planning and intra-operative guidance in modern neurosurgery: a review of 300 cases. Ann R Coll Surg Engl 81, 217-25. 